\title{
Biorefinery of the Lignocellulosic Waste of Wood Processing for Environmental Sustainability
}

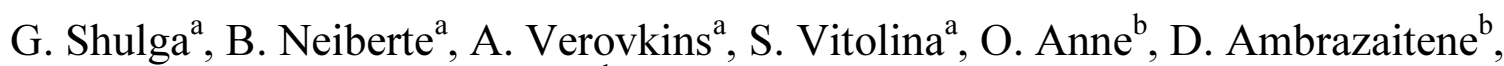 \\ A. Žukauskaite ${ }^{\mathrm{b}}$, V. Shapovalov ${ }^{\mathrm{c}}, \mathrm{A}$. Valenkov ${ }^{\mathrm{c}}$ \\ ${ }^{a}$ Latvian State Institute of Wood Chemistry, 27 Dzerbenes Str., LV-1006 Riga, Latvia \\ ${ }^{b}$ Klaipeda University, 84 H.Manto, LT-5808 Klaipeda, Lithuania \\ ${ }^{c}$ Institute of Mechanics of Metal-Polymer Systems, NAS of Belarus, 32a Kirov Str., 246050 Gomel, Belarus
}

\begin{abstract}
The lignocellulosic biomass remaining after the chemical and mechanical processing of wood in Eastern European countries is commonly used to produce energy that is not beneficial from the economic, social and environmental points of view. Owing to the notable deposits of a lignocellulosic by-product such as hydrolysis lignin in Belarus and Lithuania (as a waste of the post-hydrolysis industry), its tailored biorefinery is an urgent problem. In this paper, results of the application of the hydrolysis lignin modified with various chemical methods as a filler in the wood polymer composite and a mulch for prevention of soil erosion are presented. The obtained results testify that the purposeful modification of hydrolysis lignin by the treatment of the non-stoichiometric polyelectrolyte complex, incorporating quaternary polymeric amine and sulphate lignin, as well as by diethylepoxypropylamine with the aim of the partial replacement of the more expensive wood flour in the wood polymer composite, favours the remarkable improvement of the mechanical properties of the composite and the decrease of its ability to adsorb water. The modification of the hydrolysis lignin particles as a mulch with a non-stoichiometric polyelectrolyte complex sulphite lignin/acrylic polymer by the impregnation method creates more favourable conditions in the soil for decreasing water evaporation, increasing mulch cohesiveness and fertility of soil, in comparison with the case of the initial hydrolysis lignin.
\end{abstract}

Keywords: hydrolysis lignin; modification; mulch; polyelectrolyte complex; wood polymer composite material

\begin{tabular}{|ll}
\hline \multicolumn{2}{l}{ Nomenclature } \\
HL & hydrolysis lignin \\
MHL & modified hydrolysis lignin \\
NPEC & non-stoihiometric polyelectrolyte complex \\
RPP & recycled polypropylene \\
WPC & wood polymer composites \\
\hline
\end{tabular}

\section{Introduction}

Nowadays, a significant European emphasis is placed on the development of biorefinery concepts and maximising the utilisation of biomass wastes and by-products into value-added products. During wood mechanical and chemical processing, plenty of various kinds of lignocellulosic wastes and by-products such as sawdust, planar shavings, sanding dust, scraps and hydrolysis lignin are produced annually. Lignocellulosics as a raw material have many well-known advantages such as renewability, ecological affinity and biological degradability with transformation in soil in the nutrient forms. However, the lignocellulosic biomass remaining after the chemical and mechanical processing of wood is commonly used to produce energy, thereby reducing the fossil fuel demand and enhancing the $\mathrm{CO}_{2}$ concentration in the atmosphere.

It is known that waste lignocellulosics can be successfully used as a filler in wood-polymer composites [1-3] and as a mulch for regulation of the moisture-temperature regime of the soil surface [4-6].

Usually, wood polymer composites (WPC) consist of a lignocellulosic filler and thermoplastic polymers (polyethylene, polypropylene). These composites are made using melt compounding and injection or hot-press moulding. Due to their low

Corresponding author: G. Shulga. E-mail address: shulga@junik.lv

http://dx.doi.org/10.3846/enviro.2014.053

(C) 2014 The Authors. Published by VGTU Press. This is an open-access article distributed under the terms of the Creative Commons Attribution License, which permits unrestricted use, distribution, and reproduction in any medium, provided the original author and source are credited. 
cost and good performance, WPC find wide application in building engineering, making interiors and internal finishes, garden and outdoor products, etc. Recycling of synthetic polymers is an effective mode for reducing municipal solid wastes and plays an important part in their management. Polypropylene is the main constituent of polymeric municipal solid wastes that cause many environmental problems. An advanced practice of the joint use of recycled PP together with lignocellulosic by-products is obtaining of polymer composite materials. However, there is a low compatibility between the recycled thermoplastic polymer and the lignocellulosic filler.

The purposeful application of the lignocellulosic waste in agriculture and forestry may be also regarded as an advanced means for its utilisation. Possibilities of different types of lignocellulosic mulch for protection of the soil surface have been demonstrated [7-8]. For Eastern European countries, having well-developed wood processing, the application of lingocellulosic waste such as sawdust, bark and hydrolysis lignin as a soil mulch is economically grounded and promising.

In both cases, for successive application, a purposeful modification of lignocellulosic by-products is needed. It is known that, in obtaining WPC, it is important to regulate the hydrophilic-hydrophobic balance at the lignocellulosic surface by modification of its surface hydroxyl groups. For this aim, various chemical reagents including inorganic bases and inorganic acids, anhydrides, different types of isocyanates, formaldehyde, phthaldehydic acid, etc. are applied [9-10].

Taking into account the application of waste lignocellulosics as a mulch and natural weathering conditions, the chemical treatment of waste lignocellulosics has to promote binding together of lignocellulosic species for preventing their washout, leaching and blowing off from the soil surface [11-12], favourably influence the chemical composition of the mulched soil and favour the development of plants.

The present work is the continuation and generalisation of our studies on the developed modification methods of hydrolysis lignin for creating wood polymer composites [13-14] and a mulch material [15-17] for protection of sandy soil against erosion. Owing to the notable deposits of hydrolysis lignin in Belarus and Lithuania (as a waste of the posthydrolysis industry), the tailored biorefinery of hydrolysis lignin is an urgent problem, taking into account also the pollution problems of the environment.

\section{Materials and methods}

Hydrolysis lignin (HL), representing the remaining wide-scale waste of the hydrolysis industry, was used as an object for modification with a target of its biorefinery. For obtaining composite materials, the hydrolysis lignin from Belarus (Rechica) was used. It was extracted with hot water during $3 \mathrm{~h}$ for removing low-molecular soluble substances and admixtures, then dried at $60^{\circ} \mathrm{C}$ and milled. Fractions of the lignin particles with the size less than $0.5 \mathrm{~mm}$ dominated in its mechanical composition. Its chemical composition was the following: $\mathrm{pH} 5.5$; organic carbon $63.72 \%$; total nitrogen $0.18 \%$; hydrogen $5.86 \%$, sulphur $0.20 \%, \mathrm{OCH}_{3}$ groups content $10.60 \%$.

The hydrolysis lignin from Lithuania (Kedainai) was used for obtaining mulch. It was exempted from solid contaminants, but was not extracted by hot water. The chemical composition of the HL was the following: $\mathrm{pH}$ 5.1; organic carbon $30.91 \%$; total nitrogen $0.34 \%$; $\mathrm{OCH}_{3}$ groups' content $4.95 \%$. It also contained $\mathrm{P}_{2} \mathrm{O}_{5} 404 \mathrm{mg} \mathrm{kg}^{-1}$ and $\mathrm{K}_{2} \mathrm{O} 831 \mathrm{mg} \mathrm{kg}^{-1}$; the fractions of the lignin particles with the size between 1.0 and $2.0 \mathrm{~mm}$ and less than $0.5 \mathrm{~mm}$ dominated in its mechanical composition.

The modification of the lignocellulosic by-product was carried out by different methods. It is known that alkaline treatment can change the degree of crystallinity of cellulose by forming amorphous regions. This facilitates the access of modifiers to the wood surface. Keeping this in mind, HL particles were activated in a $0.5 \%$ sodium hydroxide solution at room temperature during $3 \mathrm{~h}\left(\mathrm{MHL}_{1}\right)$ with the following washing for removing the $\mathrm{NaOH}$ traces. Another method for modification of $\mathrm{HL}$ particles $\left(\mathrm{MHL}_{2}\right)$ was its amination with diethylepoxypropylamine (DEEPA) [18]. $\mathrm{MHL}_{3}$ and $\mathrm{MHL}_{4}$ were obtained by modification of HL with non-stoichiometric polyelectrolyte complexes (NPEC) [19], consisting of two polymers, namely, sulphate lignin/quaternary polymeric amine and sulphite lignin/acrylic polymer, respectively.

The modification of HL with NPEC sulphate lignin/polymeric amine was performed in a water medium at room temperature for $5 \mathrm{~h}$. MHL 4 was obtained by treatment of the HL particles with water solutions of the NPEC sulphite lignin/acrylic polymer with a defined composition $Z$ (a mass ratio of acrylic polymer to sulphite lignin) and a defined concentration by impregnation of the HL particles or mixing with them.

$\mathrm{MHL}_{1}, \mathrm{MHL}_{2}$ and $\mathrm{MHL}_{3}$ were applied for making WPC samples, and $\mathrm{MHL}_{4}$ was used as a mulch.

For making WPC samples, recycled polypropylene (RPP) was used as a thermoplastic polymer matrix. It had a density of $0.9 \mathrm{t} \mathrm{m}^{-3}$ and a melt flow index of $5.2 / 10 \mathrm{~min}\left(230^{\circ} \mathrm{C}, 2.16 \mathrm{~kg}\right)$. The RPP content was 50 mass \%. Another part of the WPC composition consisted of birch wood flour, a by-product of wood mechanical processing that is traditionally used for obtaining WPC, which was partially replaced with modified HL. The WPC samples were prepared by the extrusion method on an extruder "HAKKE" at temperatures of $170-180^{\circ} \mathrm{C}$ as well as by moulding under pressure at the temperature $180^{\circ} \mathrm{C}$ and dwelling time 10-15 s. Mechanical tests were carried out in a universal machine "Instron" according to GOST 1126280 and GOST 4647-80. Water sorption of the composite samples was determined using a desiccator method at a humidity of $98 \%$ and a temperature of $20 \pm 2{ }^{\circ} \mathrm{C}$ according to GOST 24816 . Water sorption was evaluated by the mass increase of the composite samples using an electron balance. The surface structure of the obtained composites was examined on a scanning electron microscope TESLA.

The Lithuanian hydrolysis lignin was used as a mulch. To study the ability of the modified HL-based mulch to withstand mechanical destruction, raw composite blends were made by mixing the HL with concentrated solutions of the NPEC 
sulphite lignin/acrylic polymer at different weight ratios with their subsequent compacting in the form of cylinders at the pressure $0.1 \mathrm{MPa}$ and duration $3 \mathrm{~min}$. The ability of the air-dried cylinders to withstand the crushing force was determined in 7 days after their preparation and was characterised by the value of compressive strength according to ASTM D695 using a universal testing machine.

Water resistance of the obtained composites prepared from the modified hydrolysis-based mulch was evaluated visually by the time ( $\mathrm{min}$ ) of the onset of the disintegration of the cylinder fully immersed in cold distilled water.

The water evaporation from a sandy soil mulched with $\mathrm{MHL}_{4}$ was evaluated from the mass loss upon its standing in the open air. For obtaining $\mathrm{MHL}_{4}$, a HL surface layer in round plastic baths filled with a sandy soil was treated with NPEC water solutions with the defined concentration and application rate by an impregnation method. After drying the obtained samples to an air-dry state, equal amounts of water were applied to the mulched surface of each bath so that the total content of moisture in all samples was equal. The water evaporation from the mulch was evaluated from the mass loss of the bath using an electron balance upon its standing in the open air and was expressed by the time (h) needed for achieving an air-dry state of soil.

The changes in the chemical composition of the mulched soil were investigated in 10 litre buckets. A HL surface layer of different thickness was placed on the soil top and modified with NPEC water solutions. The effect of the modified mulch on the chemical composition of soil was estimated based on the variation in the content of the nutrient elements during three months, two and three years after the beginning of the experiments $[15,16]$.

\section{Results and discussion}

\subsection{1. Modified HL as a filler for obtaining a wood polymer composite}

It is known that the type of the wood filler and its content in a composite material are crucial for its physico-mechanical properties. Table 1 lists the values of maximal tensile strength, Young's modulus, deformation and impact viscosity for the samples of the composite materials, containing 50 mass $\%$ of recycled PP and 50 mass $\%$ of the filler of wood origin. In this case, as the initial control sample, a system was chosen, in which the filler fully consisted of birch wood flour, because WPC, containing wood flour, are composite materials that are most often used in practice [20-21]. In other samples, 25 mass \% of wood flour (WF) was replaced by the initial $\mathrm{HL}$ and its modifications $\left(\mathrm{MHL}_{1}, \mathrm{MHL}_{2}, \mathrm{MHL}_{3}\right)$. A comparison of the obtained results (Table 1) shows that the replacement of $25 \%$ of the wood filler by the initial lignin results in the worsening of the mechanical properties of the composite, decreasing its tensile strength and Young's modulus; in this case, its tangential modulus and impact viscosity also decrease. Obviously, such an adverse effect of non-modified hydrolysis lignin on the strength properties of the composite are connected with the poor compatibility of the mixed filler with RPP and the enhancement of the heterogeneity of the composite system.

Alkaline modification of hydrolysis lignin $\left(\mathrm{MHL}_{1}\right)$, resulting in the activation of its surface, favoured the enhancement of the deformability of the composite material and a notable increase in the value of its tangential modulus, in comparison with the case of the wood flour filled composite. At the same time, the other parameters such as mechanical strength, Young's modulus and impact viscosity do not suffer any considerable changes. The notable increase in the deformability of the composite samples can be connected with the effect of its plasticisation by $\mathrm{MHL}_{1}$ particles.

The presence of quaternary amino groups at the surface of hydrolysis lignin as a result of its modification by DEEPA $\left(\mathrm{MHL}_{2}\right)$ and non-stoichiometric NPEC sulphate lignin/quaternary polymeric amine $\left(\mathrm{MHL}_{3}\right)$ resulted in a remarkable improvement of all the studied parameters. Tensile strength increased by $15-20 \%$, Young's modulus grew by $35-40 \%$, and the deformability increased almost 3-fold, compared with the case of the wood flour filled composite. The energy going into the destruction of the composite notably increased, which was testified by a $60-70 \%$ increase of impact viscosity for the $\mathrm{MHL}_{2}$ and $\mathrm{MHL}_{3}$ containing composites. The presence of positively charged amino groups at the surface of the modified HL favoured considerably the conditions of the interaction at the polymer matrix - filler interface owing to the formation of the chemical bonds of electrostatic nature, taking into account the presence of negatively charged functional groups in the recycled PP.

Table 1. Mechanical properties of composites

\begin{tabular}{|c|c|c|c|c|c|c|}
\hline $\mathrm{N}$ & Composition & $\begin{array}{l}\text { Tensile } \\
\text { strength, } \mathrm{MPa}\end{array}$ & $\begin{array}{l}\text { Modulus of elasticity, } \\
\mathrm{MPa}\end{array}$ & $\begin{array}{l}\text { Deformation, } \\
\%\end{array}$ & $\begin{array}{l}\text { Tangential } \\
\text { modulus, } \mathrm{MPa}\end{array}$ & $\begin{array}{l}\text { Impact viscosity, } \\
\mathrm{kJ} / \mathrm{m}^{2}\end{array}$ \\
\hline 1 & $50 \% \mathrm{RPP}+50 \% \mathrm{WF}$ & $15.4 \pm 1.4$ & $1127.2 \pm 7.8$ & $2.1 \pm 0.4$ & $144.8 \pm 1.9$ & $5.2 \pm 0.7$ \\
\hline 2 & $\begin{array}{l}50 \% \mathrm{RPP}+25 \% \mathrm{WF} \\
+25 \% \mathrm{HL}\end{array}$ & $14.5 \pm 1.6$ & $983.5 \pm 6.7$ & $3.7 \pm 0.4$ & $119.2 \pm 2.3$ & $4.1 \pm 0.5$ \\
\hline 3 & $\begin{array}{l}50 \% \mathrm{RPP}+25 \% \mathrm{WF} \\
+25 \% \mathrm{MHL}_{1}\end{array}$ & $15.8 \pm 0.9$ & $1011.9 \pm 5.1$ & $5.2 \pm 0.3$ & $339.7 \pm 1.7$ & $5.7 \pm 0.6$ \\
\hline 4 & $\begin{array}{l}50 \% \mathrm{RPP}+50 \% \mathrm{WF} \\
+25 \% \mathrm{MHL}_{2}\end{array}$ & $17.4 \pm 1.1$ & $1474.5 \pm 6.9$ & $6.8 \pm 0.5$ & $354.4 \pm 2.6$ & $7.5 \pm 0.4$ \\
\hline 5 & $\begin{array}{l}50 \% \mathrm{RPP}+50 \% \mathrm{WF} \\
+25 \% \mathrm{MHL}_{3}\end{array}$ & $18.1 \pm 1.2$ & $1592.1 \pm 7.2$ & $6.2 \pm 0.6$ & $420.4 \pm 2.1$ & $8.8 \pm 0.7$ \\
\hline
\end{tabular}


The presence of chemical interactions at the interface enhances the compatibility of the filler with the polymer matrix, which is reflected in the improvement of the mechanical properties of the composite and its morphology. The SEM image of the composite, containing 25 mass $\%$ of $\mathrm{MHL}_{3}$, testifies the homogeneity of the obtained structure and its consolidation (Fig. 1, a), in comparison with the composite containing $25 \%$ unmodified HL (Fig. 1, b).

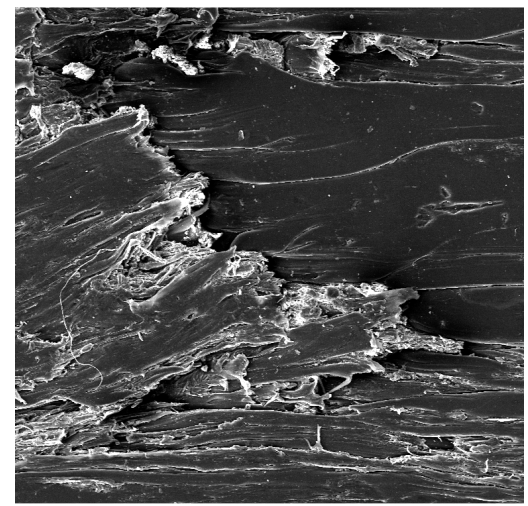

a

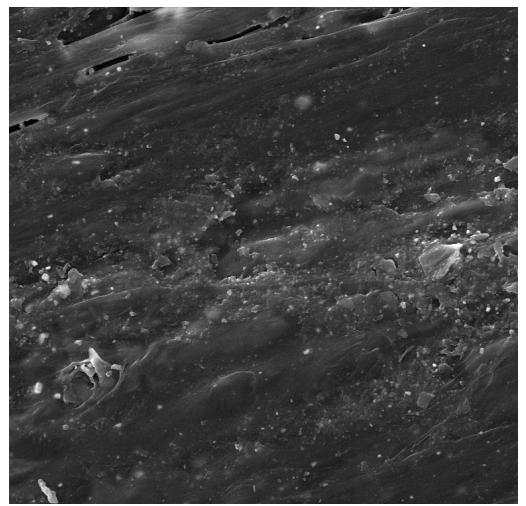

b

Fig. 1. SEM images of the composites containing $25 \%$ wood flour $/ 25 \% \mathrm{HL}$ (a) and $25 \%$ wood flour $/ 25 \% \mathrm{MHL}_{3}$ (b)

It is known that one of the essential drawbacks of WPC is their ability to adsorb water. Table 2 lists the values of the sorption of water vapours with composites, containing an equal amount of the initial and modified HL, during 30,57 and 75 days. It can be seen that the presence of the unmodified HL particles in the composite hydrophilises its surface, which manifests itself in the increase of the water vapour sorption by $22-25 \%$ on the average, compared with the sample, containing 50 mass \% of wood flavour. Filling of the composite material with $\mathrm{MHL}_{1}$ insignificantly decreases the water sorption during 30 and 57 days of observation, compared with the case of the initial composite; at the same time, the difference in the amount of the adsorbed water at the end of the experiment ( 75 days) is practically absent. The presence of the chemical interactions between the polymeric matrix and the modified HL particles $\left(\mathrm{MHL}_{2}\right.$ and $\left.\mathrm{MHL}_{3}\right)$, and as a consequence, blocking of the lyophilic groups in the polymer matrix and the modified HL, notably decrease the ability of the obtained composites to adsorb water vapours. It can be seen that, compared with the composite, containing only wood flour, the decrease in water sorption, is practically 2 -fold.

Table 2. Water sorption of composites depending on time

\begin{tabular}{lllll}
\hline $\mathrm{N}$ & Composition & & \multicolumn{2}{c}{ Water sorption, $\%$} \\
& & 30 day & 57 day & 75 day \\
\hline 1 & $50 \% \mathrm{RPP}+50 \% \mathrm{WF}$ & $5.52 \pm 0.21$ & $5.71 \pm 0.19$ & $5,83 \pm 0.17$ \\
2 & $50 \% \mathrm{RPP}+25 \% \mathrm{WF}+25 \% \mathrm{HL}$ & $6.88 \pm 0.19$ & $7.09 \pm 0.22$ & $7.12 \pm 0.15$ \\
3 & $50 \% \mathrm{RPP}+25 \% \mathrm{WF}+25 \% \mathrm{MHL}_{1}$ & $4.45 \pm 0.27$ & $4.85 \pm 0.25$ & $5.36 \pm 0.30$ \\
4 & $50 \% \mathrm{RPP}+50 \% \mathrm{WF}+25 \% \mathrm{MHL}_{3}$ & $2.81 \pm 0.18$ & $3.47 \pm 0.20$ & $3.62 \pm 0.17$ \\
5 & $50 \% \mathrm{RPP}+50 \% \mathrm{WF}+25 \% \mathrm{MHL}_{2}$ & $2.53 \pm 0.18$ & $2.81 \pm 0.15$ & $3.15 \pm 0.12$ \\
\hline
\end{tabular}

The obtained results testify that the purposeful modification of hydrolysis lignin for partial replacement of more expensive wood flour in the composition of a composite material favours the improvement of its mechanical properties and the drop in its ability to adsorb water.

\subsection{2. Modified HL as a mulch for prevention of soil erosion}

It known that, for prevention of the mulch washout and blowing off from the soil surface during the action of unfavourable climatic factors, the cohesion between mulch species should be increased remarkably. To compare the cohesion ability of the initial and the modified HL, the particles were modified with the NPEC sulphite lignin/acrylic polymer by their mixing at room temperature. The obtained raw material contained 75-95 mass \% HL particles and 5-25 mass \% NPEC. For mechanical testing, composite samples in the form of cylinders were prepared from the obtained material [17]. With increasing NPEC composition from 0.05 to 0.2 , the compressive strength of the obtained composites increased 2.1-4.5 times, which indicated the essential growth of the cohesiveness between the HL particles (Table 3). Evidently, the increase of the cohesiveness of the modified HL particles was favoured by the formation of H-bonds and Van der Waals interactions between them due to the presence of the active reaction centres at their surface in the form of weak acidic hydroxyl and carboxyl groups as well as carbonyl and ether groups as a result of their modification. 
Table 3. Characteristics of modified HL particle-based mulch

\begin{tabular}{llll}
\hline $\begin{array}{l}\text { NPEC composition, } \\
Z\end{array}$ & Compressive strength*, MPa & $\begin{array}{l}\text { Time of the onset of } \\
\text { disintegration, min }\end{array}$ & $\begin{array}{l}\text { Time of water evaporation } \\
\text { from modified HL } \\
\text { particles**, }\end{array}$ \\
\hline without modification & 0.00 & 0.00 & $816 \pm 9$ \\
0.05 & $0.29 \pm 0.09$ & $19 \pm 3$ & $1056 \pm 7$ \\
0.1 & $0.43 \pm 0.05$ & $25 \pm 1$ & $1152 \pm 3$ \\
0.2 & $0.57 \pm 0.07$ & $28 \pm 1$ & $1248 \pm 4$ \\
\hline${ }^{* *}$ content of HL particles -75 mass $\%$ & &
\end{tabular}

The more developed system of the interfacial physico-chemical bonds between the modified HL species had a favourable effect on the hydrophobicity of the obtained composite materials that was expressed by a more pronounced water resistance. With increasing composition of the NPEC from 0.05 to 0.20 , the time of the onset of disintegration for the composite cylinders made from the treated hydrolysis lignin particles increased 1.3-1.5 times (Table 3).

The main function of any mulch is to regulate the water-temperature regime at the soil surface. It was found that the time required for moisture evaporation from the soil covered with the modified HL particles varied in the range of 38-52 days and depended on the composition of the NPEC, the concentration of its solution and the application rate. This time essentially exceeded the time of moisture evaporation from the soil covered with initial HL. With increasing composition of the NPEC at the same concentration and application rate, the mulching effect tended to grow (Table 3). On the average, the time of moisture evaporation from the soil samples covered with the modified HL particles exceeded by $29-52 \%$ the time of moisture evaporation from the samples covered with untreated HL.

To study of the effect of the modified HL particles on the chemical composition of sandy soil, they were modified with NPEC sulphite lignin/acrylic polymer water solutions by the impregnation method. The concentration of water solutions of NPEC having the minimal and the maximal $Z$ values as well as their application rate were chosen, keeping in mind the results of the moisture evaporation from the sandy soil covered with the modified HL. The changes in the chemical composition of the sandy soil without and covered with the HL mulch were defined for the first year, but the content of organic $\mathrm{C}$ and organic $\mathrm{N}$ were also analysed for the second and third years of the investigation.

Table 4. Changes in the chemical composition of sandy soil covered by the hydrolysis lignin modified with the NPEC water solution by the impregnation method (concentration $-100 \mathrm{~g}^{-1}$, application rate $-4.01 \mathrm{~m}^{-2}$ )

\begin{tabular}{|c|c|c|c|c|c|c|c|}
\hline \multirow{2}{*}{$\begin{array}{l}\mathrm{HL} \\
\text { layer, } \\
\mathrm{cm}\end{array}$} & \multirow{2}{*}{$\begin{array}{l}\text { NPEC } \\
\text { composition, Z }\end{array}$} & \multirow{2}{*}{$\begin{array}{l}\mathrm{pH} \\
\text { of soil }\end{array}$} & \multirow{2}{*}{$\begin{array}{l}\mathrm{P}_{2} \mathrm{O}_{5} \\
\mathrm{Mgkg}^{-1}\end{array}$} & \multirow{2}{*}{$\begin{array}{l}\mathrm{K}_{2} \mathrm{O} \\
\mathrm{mgkg}^{-1}\end{array}$} & \multicolumn{3}{|c|}{$\mathrm{C} / \mathrm{N}$} \\
\hline & & & & & 1st year & 2nd year & 3rd year \\
\hline 0 & $\begin{array}{l}\text { Unmulched soil } \\
\text { without treatment }\end{array}$ & 6.6 & 191 & 50 & 6.10 & 7.3 & 8.3 \\
\hline 0 & $\begin{array}{l}\text { Soil treated with } \\
Z=0.05\end{array}$ & 6.6 & 194 & 59 & 26.0 & 4.2 & 3.5 \\
\hline 0 & $\begin{array}{l}\text { Soil treated with } \\
Z=0.20\end{array}$ & 6.4 & 220 & 54 & 12.5 & 14.3 & 8.9 \\
\hline 2 & Initial HL & 6.2 & 199 & 80 & 26.70 & 33.6 & 26.9 \\
\hline 2 & $\begin{array}{l}\text { HL treated with } \\
Z=0.05\end{array}$ & 6.2 & 197 & 79 & 94.40 & 32.3 & 25.0 \\
\hline 2 & $\begin{array}{l}\text { HL treated with } \\
Z=0.20\end{array}$ & 6.4 & 213 & 75 & 84.70 & 41.4 & 20.0 \\
\hline 5 & Initial HL & 6.0 & 217 & 132 & 63.90 & 39.0 & 30.6 \\
\hline 5 & $\begin{array}{l}\text { HL treated with } \\
Z=0.05\end{array}$ & 6.1 & 216 & 91 & 92.50 & 36.0 & 45.4 \\
\hline 5 & $\begin{array}{l}\text { HL treated with } \\
Z=0.02\end{array}$ & 6.1 & 217 & 209 & 69.80 & 39.7 & 42.3 \\
\hline
\end{tabular}

It was found (Table 4) that the acidity of the sandy soil mulched with unmodified HL increased with increasing the mulch layer. At the same time, the modified HL decreased the acidity of sandy soil. The quantity of mobile $\mathrm{P}_{2} \mathrm{O}_{5}$ and $\mathrm{K}_{2} \mathrm{O}$ forms in the soil mulched with the modified HL was enhanced, depending on its thickness and the NPEC composition. According to the obtained results, the impregnation of a $5 \mathrm{~cm}$ layer of HL with the NPEC solution with $\mathrm{Z}=0.2$ enhanced the $\mathrm{K}_{2} \mathrm{O}$ content in soil almost 1.7-fold relative to the soil, mulched with the HL. The obtained results indicated that the 
impregnation of hydrolysis lignin with the NPEC solutions allowed enriching sandy soil with the useful nutrient elements, needed for the development of grass and plants [15].

The modification of HL with NPEC influenced also the values of the $\mathrm{C} / \mathrm{N}$ ratio in soil. The total amount of carbon tended to increase with enhancing the thickness of the applied modified HL mulch layer (Table 4). In the untreated soil, the $\mathrm{C} / \mathrm{N}$ ratio was equal to 6.1 , which indicated that the mineralisation process proceeded slowly. When the HL particles were impregnated with the NPEC solutions, the $\mathrm{C} / \mathrm{N}$ ratio in soil was increased 11-16 times, on the average, relative to untreated soil, and 1.5-3.5 times relative to the soil covered with unmodified HL mulch. On the third year, the $\mathrm{C} / \mathrm{N}$ ratio for the soil covered with a $2 \mathrm{~cm}$ and $5 \mathrm{~cm}$ layer of the modified HL particles decreased 3.7-4.2 times and 1.7-4.1 times, respectively, relative to this index of the first year (Table 4). This indicated the intensive chemical transformations that proceeded in sandy soil covered with the HL particles modified with the NPEC. Our investigations have shown that micro-mycetes played a leading role in the process of the biochemical degradation of modified HL in soil [16].

\section{Conclusion}

The obtained results testify that the purposeful modification of hydrolysis lignin by the treatment of the non-stoichiometric polyelectrolyte complex, incorporating quaternary polymeric amine and sulphate lignin, and DEEPA with the aim of the partial replacement of more expensive wood flour in the wood polymer composite favours the improvement of the mechanical properties of the composite and the decrease of its ability to adsorb water.

The modification of the HL particles as a mulch with a non-stoichiometric polyelectrolyte complex sulphite lignin/acrylic polymer by the impregnation method creates more favourable conditions in the soil for decreasing water evaporation, increasing mulch cohesiveness and fertility of soil in comparison with the case of the unmodified HL.

\section{Acknowledgment}

The scientific investigations, the results of which are presented in this work, were financed by the Latvian National Research Programme-5, the Latvian-Belarus bilateral project and the EUREKA E! 2622 project.

\section{References}

[1] Stark, N.; Rowlanders, R. E. 2003. Effects of wood fiber characteristics on mechanical properties of wood/polypropylene composites, Wood Fiber Science 35(2): 167-174

[2] Bledzki; A. K.; Faruk, O. 2005. Surface roughness, impact, and odor properties microcellular wood fiber reinforced PP composites: cell morphology, Journal of Cellular Plastics 41: 539-550.

[3] Hugo, A. V.; Scelsi, L.; Hodzic, A.; Jones, F. R.; Dwyer-Joyce, R. 2011. Development of recycled polymer composites for structural applications, Plastics, Rubber and Composites: Macromolecular Engineering 40(6-7): 317-323. http://dx.doi.org/10.1179/1743289810Y.0000000008

[4] Rickson, R. J. 1995. Simulated vegetation and geotextiles, in Slope Stabilization and Erosion Control: A Bioengineering Approach. Morgan RPC, Rickson R J (eds.). E \& FN Spon, London, 95-131.

[5] Rajor, A.; Sharma, P.; Sood, V. K.; Ramamurthy V. 1996. A sawdust-derived soil conditioner promotes plant growth and improves water-holding capacity of different types of soils, Journal of Industrial Microbiology 16: 237-240. http://dx.doi.org/10.1007/BF01570027

[6] Yadav, K. R.; Sharma, R. K.; Kothari, R. M. 2002. Bioconversion of eucalyptus bark waste into soil conditioner, Bioresource Technology 81: 163-165. http://dx.doi.org/10.1016/S0960-8524(01)00061-X

[7] Calatrava, J.; Franco, J. A. 2011. Using pruning residues as mulch: Analysis of its adoption and process of diffusion in Southern Spain olive orchards, Journal of Environmental Management 92: 620-629. http://dx.doi.org/10.1016/j.jenvman.2010.09.023

[8] Curnoe, W. E.; Irving, D. C.; Dow, C. B.; Velema, G.; Unc, A. 2006. Effect of spring application of a paper mill soil conditioner on corn yield, Agronomy Journal 98: 423-429. http://dx.doi.org/10.2134/agronj2005.0041

[9] Belgacem, M. N.; Gandini, A. 2005. Surface Modification of Cellulose Fibres, Polímeros: Ciência e Tecnologia 15(2): 114-121. http://dx.doi.org/10.1590/S0104-14282005000200010

[10] Kabir, M. M.; Wang, H.; Lau, K. T.; Cardona, F. 2012. Chemical treatments on plant-based natural fibre reinforced polymer composites: an overview, Composites: Part B 43: 2883-2892. http://dx.doi.org/10.1016/j.compositesb.2012.04.053

[11] Shulga, G.; Rekners, F.; Varslavans, J. 2001. Lignin-based interpolymer complexes as a novel adhesive for protection against erosion of sandy soil, Journal of Agricultural Engineering Research 78(3): 309-316. http://dx.doi.org/10.1006/jaer.2000.0599

[12] Shulga, G.; Betkers, T.; Shakels, V.; Verovkins, A.; Neiberte, B.; Klayvinsh, I.; Kolesnikovs, G. 2008. Lignocellulosic composites obtained with the lignin-based binder for forestry needs, in Book of Abstracts "Characterisation and application of cell wall macromolecules", COST Action E50/International Lignin Institute Workshop, CH-Dubendorf, Switzerland, 2008. 35-36.

[13] Shulga, G.; Neiberte, B.; Verovkins, A.; Laka, M.; Chernyavskaya, S.; Shapovalov, V.; Valenkov, A.; Tavroginskaya, M. 2009. The new polymer composites integrating modified wood originated products, in Proc. of the International Conference Italic-5, Varenna, Italy, $2009.185-188$.

[14] Laka, M.; Chernyavskaya, S.; Shulga, G.; Shapovalov, V.; Valenkov, A.; Tavroginsakya, M. 2011. Use of Cellulose-Containing Fillers in Composites with Polypropylene, Materials Science (Medžiagotyra) 17(2): 151-154.

[15] Belous, O.; Ambrazaitene, D.; Žukauskaite, A.; Shulga G. 2006. Utilization of Lignin Waste for Preventing Soil Erosion, Environmental Research, Engineering and Management 1(35): 43-51.

[16] Ambrazaitienè, D.; Belous, O.; Žukauskaitè, A.; Shulga, G. 2006. Biodegradation of substrates used for soil erosion prevention. Ekologija 2: 59-65.

[17] Shulga, G.; Betkers, T.; Shakels, V.; Neiberte, B.; Verovkins, A.; Brovkina J.; Belous, O.; Ambrazaitene, D.; Žukauskaite, A. 2007. Effect of the modification of lignocellulosic materials with a lignin-polymer complex on their mulching properties, BioResources 2(4): 572-582.

[18] Verovkins, A.; Neiberte, B.; Shulga, G.; Shapovalov, V. Valenkov, A.; Tavroginskaya, M. 2010. Modified bark as a filler in polymer composites, in Proc. of the 11th European Workshop on Lignocellulosics and Pulp, Hamburg, Germany, 2010, 235-238. 
[19] Shulga, G.; Shakels, V.; Aniskevicha, O.; Zakharova, J.; Skudra, S. 2009. Interfacial properties of polyelectrolyte complexes incorporating kraft lignin, Holzforschung 63(6): 711-714.

[20] Ghahry, S.; Kazemi-Najafi, S.; Mohebby, B.; Tajvidi, M. 2012. Impact strength improvement of wood flour-recycled polypropylene composites, Journal of Applied Polymer Science 124(2): 1074-1080. http://dx.doi.org/10.1002/app.34015

[21] Wang, Y.; Cao, J.; Zhu, L. 2011. Stress Relaxation of Wood Flour/Polypropylene Composites at Room Temperature, Wood and Fiber Science 43(3): 262-270. 